Vol. 1 No. 1, Feb 2021, hlm. 95 - 102

DOI: https://doi.org/10.33330/.v1i1.1053

Available online at https://jurnal.stmikroyal.ac.id/index.php/jutsi

\title{
PEMETAAN SEKOLAH MDTA ISLAMIYAH BERBASIS WEB DI KABUPATEN ASAHAN
}

\author{
Okmaya $^{1}$, Juna Eska ${ }^{2 *}$, Mardalius ${ }^{3}$ \\ ${ }^{1}$ Mahasiswa Prodi Sistem Informasi, STMIK Royal \\ ${ }^{2}$ Prodi Sistem Komputer, STMIK Royal \\ ${ }^{3}$ Prodi Sistem Informasi, STMIK Royal \\ *email: dosen.junaeska@gmail.com
}

\begin{abstract}
MDTA's school mapping geographic information system is built on a web basis, and can be accessed accurately and effectively anywhere and anytime as long as the user is connected to the internet. The making of this system uses xampp software as localhost and sublime to create a website design by coding process. Google maps as an online map showing the locations of MDTA schools in Asahan District. The final result of this research is in the form of a web-based MDTA Islamiyah school mapping application in Asahan District that can be accessed by the community online, and can make it easier for the community to find school locations, especially parents to register their children at the MDTA school.
\end{abstract}

Keywords:Mapping, Islamic MDTA School, WebGIS

\begin{abstract}
Abstrak:Sistem informasi geografis pemetaan sekolah MDTA dibangun dengan berbasis web, dan dapat di akses secara tepat dan efektif dimanapun dan kapanpun selama pengguna terkoneksi dengan internet. Pembuatan sistem ini memanfaatkan software xampp sebagai localhost dan sublime untuk membuat desain website secara proses coding. Google maps sebagai peta online yang menampilkan lokasi sekolah MDTA yang berada di Kabupaten Asahan. Hasil akhir penelitian ini berupa aplikasi pemetaan sekolah MDTA islamiyah berbasis web di Kabupaten Asahan yang dapat diakses oleh masyarakat secara online, dan dapat memudahkan masyarakat dalam mencari lokasi sekolah, khususnya orang tua untuk mendaftarkan anaknya ke sekolah MDTA.
\end{abstract}

Kata Kunci:Pemetaan, Sekolah MDTA Islamiyah, WebGIS

\section{PENDAHULUAN}

Sistem merupakan kumpulan komponen yang saling berkaitan untuk mencapai tujuan yang sama [1]-[3] Informasi merupakan data yang diolah yang bermanfaat dalam pengambilan keputusan [4]. Sistem Informasi Geografis adalah sistem yang digunakan untuk menyimpan dan memanipulasi informasi yang berkaitan dengan data geografis [5]-[7]. 
Vol. 1 No. 1, Feb 2021, hlm. 95 - 102

DOI: https://doi.org/10.33330/.v1i1.1053

Available online at https://jurnal.stmikroyal.ac.id/index.php/jutsi

Dalam peningkatan Sumber Daya Manusia Indonesia, pemerintah melaksanakan berbagai upaya. Satu dari upaya tersebut adalah melalui pembangunan pendidikan, karena pendidikan merupakan suatu asset yang berguna untuk setiap orang dalam meningkatkan kualitas hidup manusia. Tanpa adanya pendidikan, taraf hidup standar kualitas seorang manusia dikatakan akan berdampak buruk. Karena pendidikan adalah sebuah proses pembelajaran agar insan manusia secara aktif mengembangkan dirinya untuk kecerdasan, kepribadian dan akhlak mulia [8].

Sekolah Madrasah Diniyah Takmiliyah Awaliyah (MDTA) adalah lembaga pendidikan keagamaan islam yang mengajarkan tentang nilai-nilai keagamaan islam. MDTA pendidikan agama islam tingkat dasar yang diselenggarakan selama 4 (empat) tahun dan jumlah belajarnya 18 jam dalam seminggu [9]. Sekolah MDTA tersebar luas di Kabupaten Asahan, yang berdiri di bawah naungan Kementerian Agama Kabupaten Asahan. Karena banyaknya tersebar luas sekolah MDTA maka mengakibatkan kurang efisiensi masyarakat dalam pencarian letak lokasi dan informasi sekolah MDTA.

Adapun tujuan dari penelitian ini adalah: (1) Membangun sistem informasi pemetaan sekolah MDTA Islamiyah yang ada di Kabupaten Asahan berbasis web., (2) memberikan informasi secara lengkap dan aktual khususnya mengenai sekolah MDTA Islamiyah di Kabupaten Asahan., (3) Untuk mengetahui arah lokasi sekolah MDTA Islamiyah di Kabupaten Asahan.

\section{METODE}

Teknik pengumpulan data dalam penelitian ini yaitu: (1) Observasi merupakan metode pengumpulan data yang dilakukan dengan cara mengamati dan mencatat secara sistematik data sekolah MDTA yang ada di Kabupaten Asahan., (2) Wawancara yaitu Wawancara adalah proses tanya jawab dalam penelitian yang berlangsung secara lisan kepada pihak Kementerian Agama bagian MDTA (Madrasah Diniyah Takmiliyah Awaliyah)., (3) Studi Pustaka merupakan metode pengumpulan data dan informasi yang dilakukan dengan kegiatan kepustakaan melalui jurnal-jurnal, penelitian terdahulu dan lain sebagainya yang berkaitan dengan penelitian yang sedang dilakukan [10].

\section{Perancangan Sistem}

Perancangan sistem adalah penggambaran, perancangan dan pembuatan sketsa sebuah sistem yang akan dibuat supaya dapat memberikan gambaran yang jelas kepada pengguna agar lebih memahami sistem yang akan dibuat dan diharapkan dapat menggunakannya dengan baik. Dalam hal ini, penulis menggunakan beberapa alat bantu untuk membangun sistem pencarian sekolah MDTA di wilayah Kabupaten Asahan. Alat bantu ini akan diuraikan dengan proses kerja yang berkaitan dengan proses perancangan Pemetaan Sekolah MDTA Islamiyah di Kabupaten Asahan.

\section{Use Case Diagram}

Dengan menggunakan Use Case Diagram akan terlihat bagaimana alur interaksi antara user dengan sistem. Berikut Use Case Diagram Pemetaan Sekolah MDTA Islamiyah di Kabupaten Asahan. 
Vol. 1 No. 1, Feb 2021, hlm. 95 - 102

DOI: https://doi.org/10.33330/.v1i1.1053

Available online at https://jurnal.stmikroyal.ac.id/index.php/jutsi

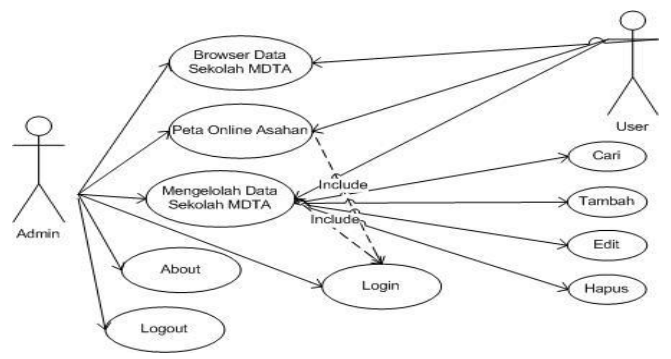

Gambar 1. Use Case Diagram

\section{Perancangan Activity Diagram}

Activity diagram merupakan menggambarkan aliran aktivitas pada perangkat lunak yang akan dibangun

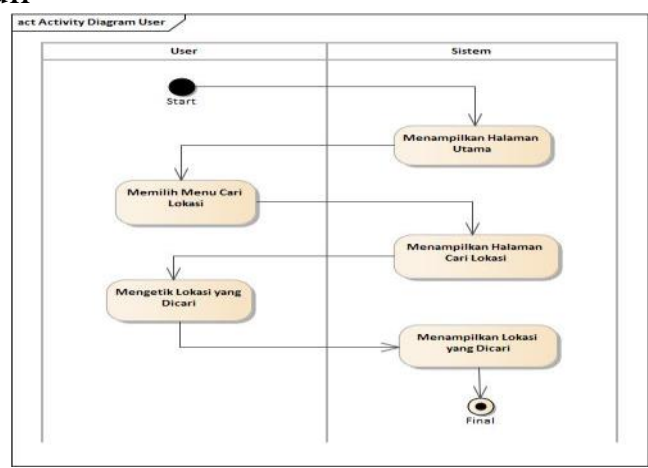

Gambar 2. Use Case Diagram

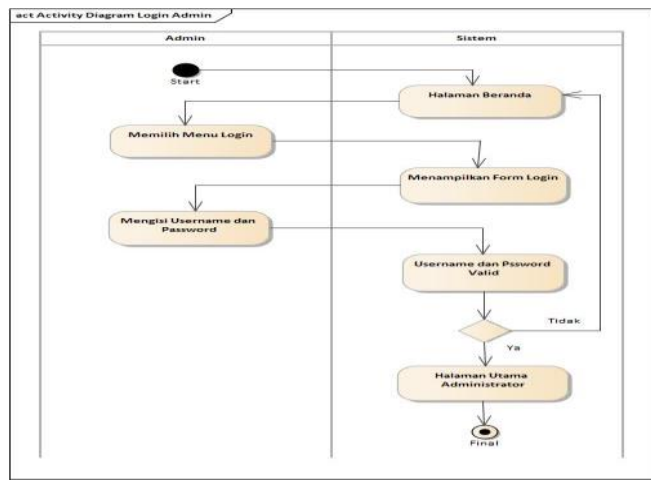

Gambar 3. Activity Diagram Admin Login

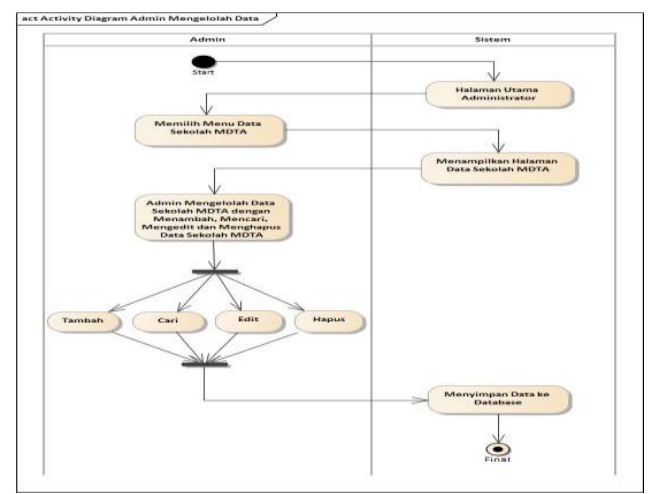

Gambar 4. Activity Diagram Admin Mengolah Data 
Vol. 1 No. 1, Feb 2021, hlm. 95 - 102

DOI: https://doi.org/10.33330/.v1i1.1053

Available online at https://jurnal.stmikroyal.ac.id/index.php/jutsi

\section{Perancangan Sequence Diagram}

Sequence Diagram adalah diagram yang menggambarkan proses yang terjadi pada sistem. Berikut ini adalah Sequence Diagram dari Sistem Informasi Geografis Pemetaan Sekolah MDTA Islamiyah di Kabupaten Asahan:

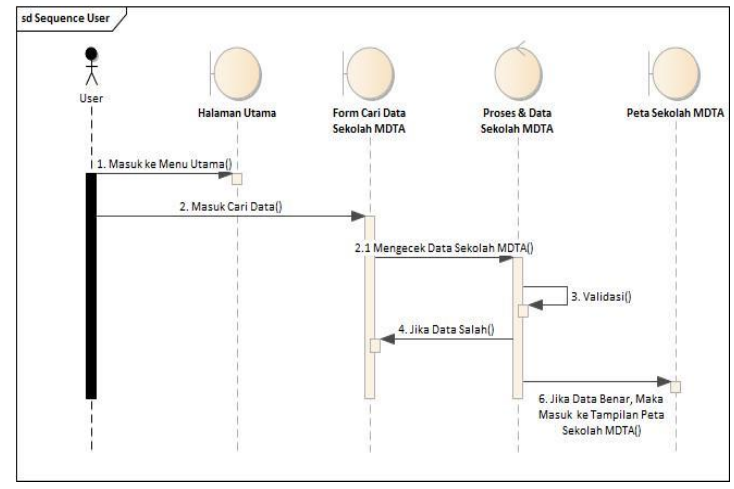

Gambar 5. Sequence Diagram

\section{Perancangan Class Diagram}

Class Diagram adalah diagram yang menggambarkan kelas-kelas yang ada dalam sistem aplikasi. Berikut ini adalah Class Diagram dari Sistem Informasi Geografis Pemetaan Sekolah MDTA Islamiyah di Kabupaten Asahan:

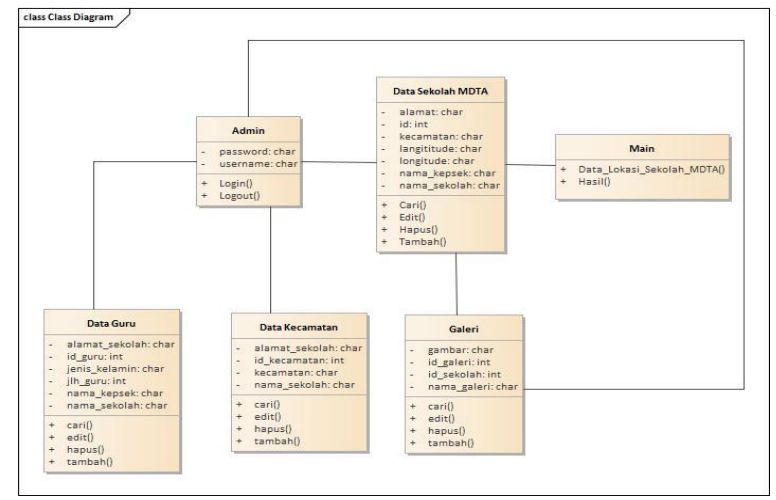

Gambar 6. Use Case Diagram

\section{HASIL DAN PEMBAHASAN}

Hasil dan pembahasan penelitian ini seperti tampak pada gambar berikut:

\section{Tampilan Halaman Utama}

Halaman utama ini merupakan halaman awal dari sistem yang telah dibuat. Halaman ini akan diakses luas oleh admin dan masyarakat untuk mengetahui lokasi dari sekolah MDTA Islamiyah di Kabupaten Asahan. Berikut ini tampilannya: 
Vol. 1 No. 1, Feb 2021, hlm. 95 - 102

DOI: https://doi.org/10.33330/.v1i1.1053

Available online at https://jurnal.stmikroyal.ac.id/index.php/jutsi

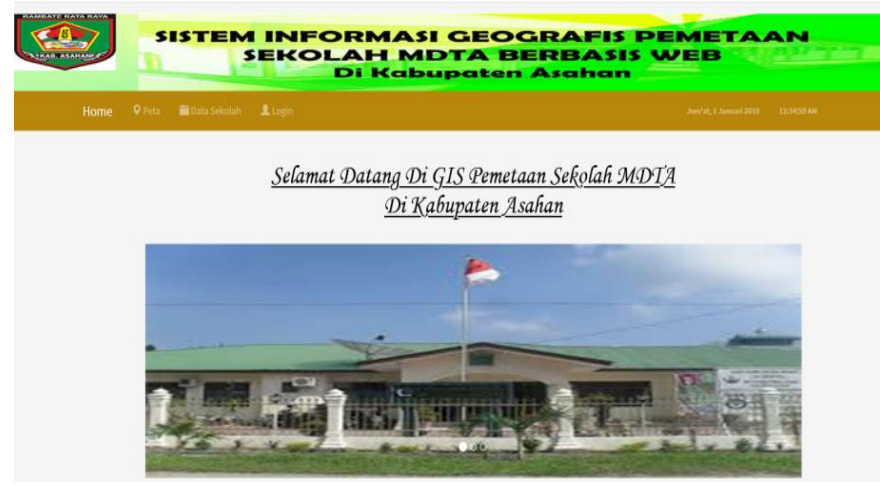

Gambar 7. Tampilan Halaman Utama

\section{Tampilan Halaman Peta Lokasi Sekolah MDTA Islamiyah}

Halaman ini menjelaskan tampilan persebasaran sekolah mdta dalam bentuk peta yang ada di SIG Pemetaan Sekolah MDTA Islamiyah di Kabupaten Asahan. Berikut tampilan peta lokasi Sekolah MDTA Islamiyah di Kabupaten Asahan :

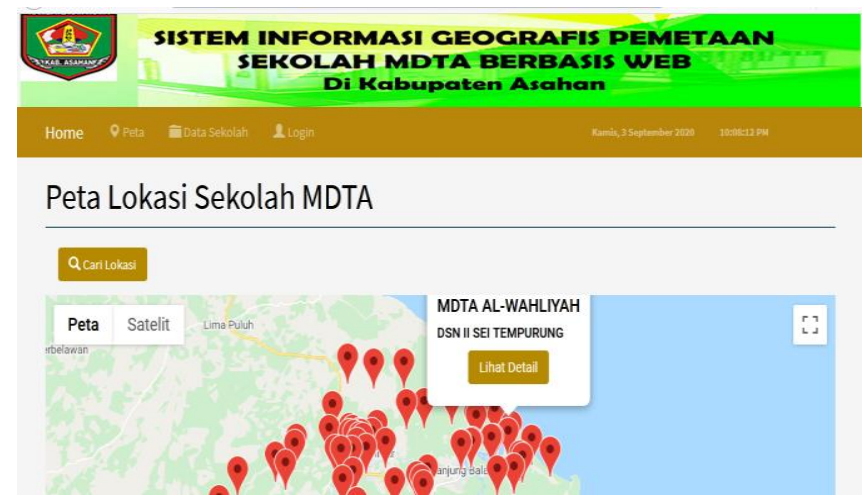

Gambar 8. Tampilan Halaman Peta Lokasi Sekolah MDTA Islamiyah

\section{Tampilan Halaman Informasi Detail Sekolah MDTA Islamiyah}

Halaman ini menjelaskan tampilan informasi detail sekolah mdta yang ada di SIG Pemetaan Sekolah MDTA Islamiyah di Kabupaten Asahan. Berikut tampilan informasi detail Sekolah MDTA Islamiyah di Kabupaten Asahan :

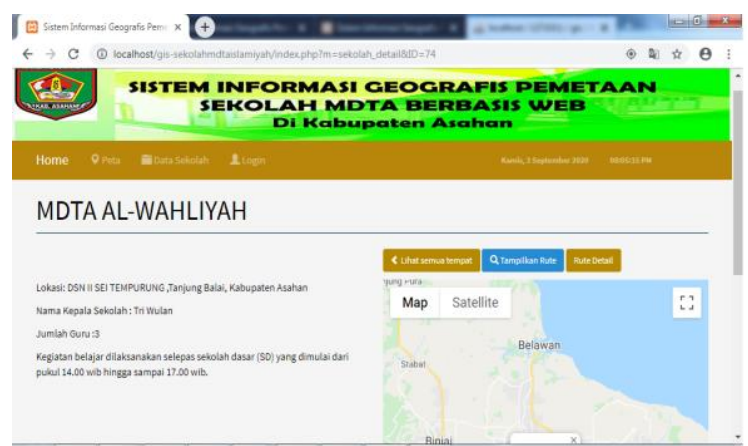

Gambar 9. Tampilan Halaman Informasi Detail Sekolah MDTA Islamiyah 
Vol. 1 No. 1, Feb 2021, hlm. 95 - 102

DOI: https://doi.org/10.33330/.v1i1.1053

Available online at https://jurnal.stmikroyal.ac.id/index.php/jutsi

\section{Tampilan Halaman Rute Detail Sekolah MDTA Islamiyah}

Halaman ini menjelaskan arah dan jarak untuk menuju sekolah MDTA yang diinginkan sehingga memudahkan pengguna. Berikut tampilan rute detail Sekolah MDTA Islamiyah di Kabupaten Asahan :

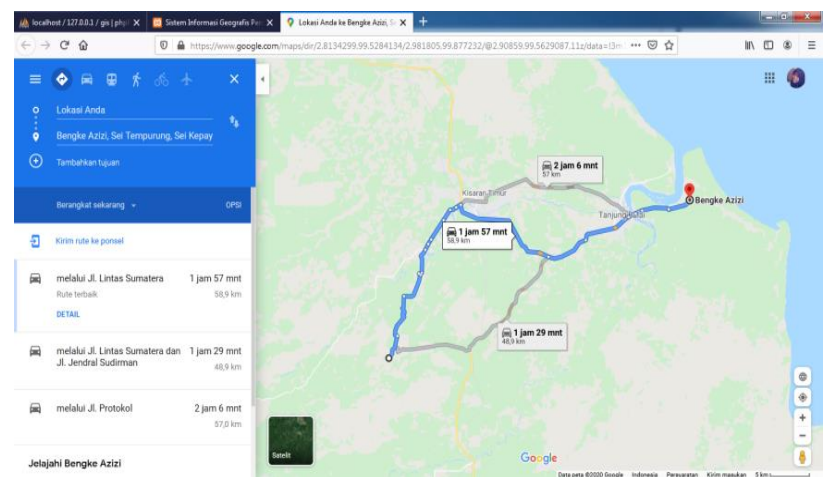

Gambar 10. Tampilan Halaman Rute Detail Sekolah MDTA Islamiyah

\section{Tampilan Halaman Login}

Halaman login merupakan halaman yang akan digunakan admin untuk masuk ke sistem dan melakukan proses input data sekolah MDTA. Berikut tampilan login Sekolah MDTA Islamiyah di Kabupaten Asahan :

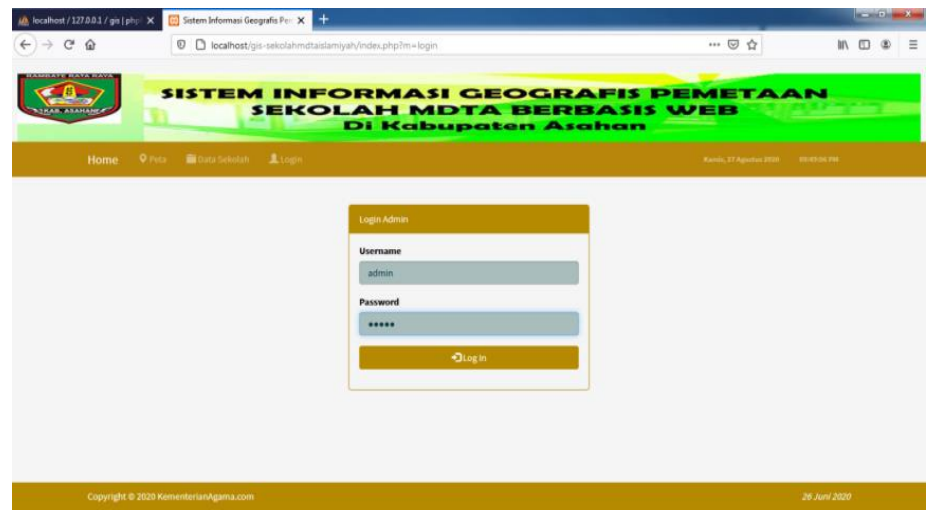

Gambar 11. Tampilan Halaman Login

\section{Tampilan Halaman Data Sekolah MDTA Islamiyah}

Tampilan data sekolah mdta islamiyah merupakan halaman untuk admin mengolah data sekolah mdta seperti menambah, mengubah dan menghapus. Berikut halaman data Sekolah MDTA Islamiyah di Kabupaten Asahan : 
Vol. 1 No. 1, Feb 2021, hlm. 95 - 102

DOI: https://doi.org/10.33330/.v1i1.1053

Available online at https://jurnal.stmikroyal.ac.id/index.php/jutsi

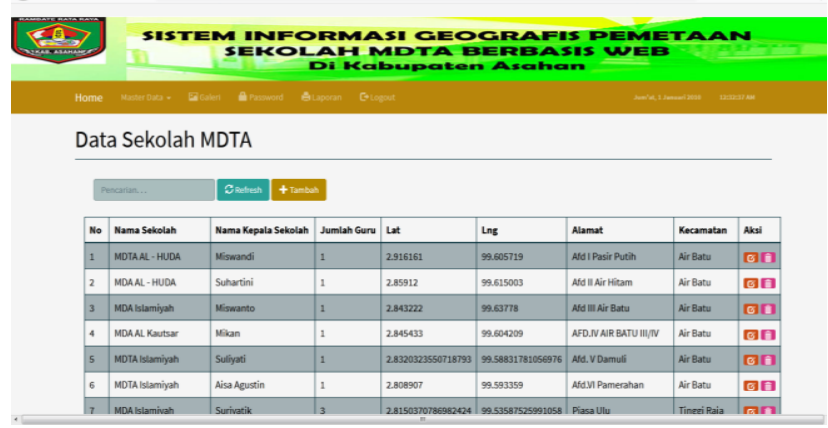

Gambar 12. Tampilan Halaman Data Sekolah MDTA

\section{Tampilan Halaman Laporan}

Berikut ini adalah tampilan halaman laporan seluruh data Sekolah MDTA Islamiyah di Kabupaten Asahan :

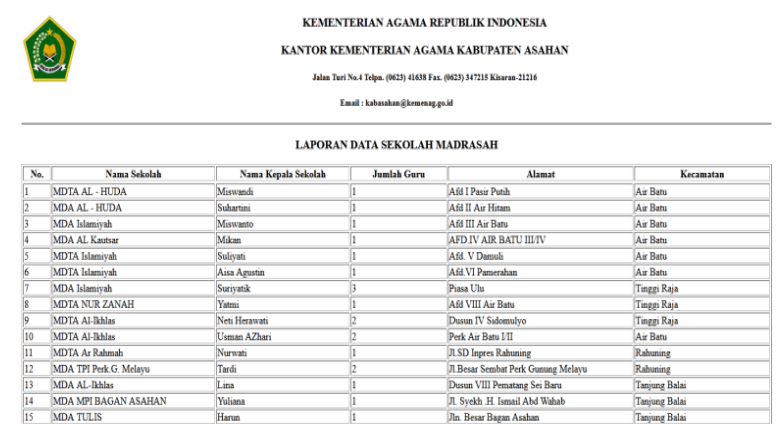

Gambar 13. Tampilan Halaman Laporan

\section{SIMPULAN}

Berdasarkan hasil dari implementasi dan pengujian yang telah dilakukan selama membuat Sistem Informasi Geografis Pemetaan Sekolah MDTA Islamiyah di Kabupaten Asahan ini, maka dapat diambil kesimpulan adalah Sistem Informasi Geografis Pemetaan Sekolah MDTA Islamiyah di Kabupaten Asahan dikembangkan dengan berbasis web. Sistem ini dilengkapi dengan tampilan rute dari lokasi awal pengguna untuk menuju Sekolah MDTA yang dituju, sehingga memberi kemudahan untuk pengguna menuju Sekolah MDTA yang akan dituju.

\section{DAFTAR PUSTAKA}

[1] S. Maharani, "SISTEM INFORMASI GEOGRAFIS PEMETAAN MASJID DI SAMARINDA BERBASIS WEB," J. Inform., 2017, doi: 10.26555/jifo.v11i1.a5205.

[2] S. Kosasih, "SISTEM INFORMASI GEOGRAFIS PEMETAAN TEMPAT KOST BERBASIS WEB," CSRID (Computer Sci. Res. Its Dev. Journal), 2015, 
Vol. 1 No. 1, Feb 2021, hlm. 95 - 102

DOI: https://doi.org/10.33330/.v1i1.1053

Available online at https://jurnal.stmikroyal.ac.id/index.php/jutsi

doi: 10.22303/csrid.6.3.2014.171-181.

[3] M. Mardalius, "GEOGRAPHIC INFORMATION SYSTEM MAPPING SPREAD OF COVID-19 WITH FRAMEWORK CODEIGNITER,” vol. 4509, no. 1, pp. 1-7, 2020.

[4] A. Annugerah, I. F. Astuti, and A. H. Kridalaksana, "Sistem Informasi Geografis Berbasis Web Pemetaan Lokasi Toko Oleh-Oleh Khas Samarinda," Inform. Mulawarman J. Ilm. Ilmu Komput., 2016, doi: 10.30872/jim.v11i2.213.

[5] Harison and A. Syarif, "Sistem informasi geografis sarana pada kabupaten pasaman barat," J. TEKNOIF, 2016.

[6] A. D. Elisanti, "Pemetaan Status Gizi Balita di Indonesia," Indones. J. Heal. Sci., 2017, doi: 10.24269/ijhs.v1i1.2017.pp37-42.

[7] Rastuti, L. A. Abdillah, and E. P. Agustini, "Sistem Informasi Geografis Potensi Wilayah," 2015.

[8] A. Hijriani, K. Muludi, and E. A. Andini, "Implementasi Metode Regresi Linier Sederhana Pada Penyajian Hasil Prediksi Pemakaian Air Bersih Pdam Way Rilau Kota Bandar Lampung Dengan Sistem Informasi Geofrafis," Inform. Mulawarman J. Ilm. Ilmu Komput., 2016, doi: 10.30872/jim.v11i2.212.

[9] G. W. Sasmito, "Penerapan Metode Waterfall Pada Desain Sistem Informasi Geografis Industri Kabupaten Tegal," J. Inform. Pengemb. IT, 2017.

[10] R. Asmara and Alhamidi, "Pengolahan data rehabilitasi penyalahgunaan narkoba pada klinik aqilah Payakumbuh," J-Click, 2017. 